\title{
Injury risk and a tackle ban in youth Rugby Union: reviewing the evidence and searching for targeted, effective interventions. A critical review
}

\author{
Ross Tucker, ${ }^{1}$ Martin Raftery, ${ }^{2}$ Evert Verhagen ${ }^{3}$
}

\begin{abstract}
${ }^{1}$ Department of Medicine, University of the Free State, Bloemfontein, South Africa ${ }^{2}$ World Rugby Pty (Ltd), Dublin, Ireland

${ }^{3}$ Amsterdam Collaboration on Health \& Safety in Sports, Vrije University Amsterdam, Amsterdam, The Netherlands
\end{abstract}

\section{Correspondence to} Dr Ross Tucker, Department of Medicine, University of the Free State, 5 Bain Court, Rondebosch 7700,

South Africa;

ross.tucker@mweb.co.za

Accepted 31 May 2016 Published Online First 20 June 2016

\section{ABSTRACT}

It has recently been proposed that the tackle, an integral part of Rugby Union, be banned in school rugby, as a means to reduce the risk of injury. This proposal held that harmful contact should be removed in response to what was termed an unacceptably high-injury risk. Such a ban would represent a significant intervention that could change the nature of Rugby Union. As such, the basis and rationale for such a ban is worthy of critical evaluation. This review aims to describe the research on which such a ban is proposed. It does so through an assessment (identification), estimation (understanding of the magnitude and occurrence) and evaluation (determining acceptability) of the risk before decisions can be made about implementing any risk mitigation strategies. The body of literature describing injury risk, particularly among youths, is indeed thin and fraught with methodological differences that makes definitive conclusions impossible. We describe these, and their implications, arguing that the complete ban on the tackle may be unnecessary in young children, in whom injury risk may not be as high as is often argued, but also that it may have detrimental consequences. Finally, we propose alternative strategies and research questions which must be pursued to effectively reduce risk without creating unintended consequences or changing the nature of the sport.

Rugby Union has made considerable strides in providing evidence-based protection of the health and well-being of players at all levels of play from the inherent risk of injury as a result of the contact nature of the game. Notably, after the scrum was identified as having a high propensity for injury, ${ }^{1}$ engagement strategies were changed on the basis of research studies, resulting in reduced biomechanical loading on front row players by $\sim 20 \% .^{2}$ This research ultimately led to a worldwide law amendment across all levels of the game.

Separately, the introduction of a new pitchside process for the assessment of head injuries in 2012 reduced the number of players who continued to play and were later diagnosed with concussion. ${ }^{3}$ This has provided the foundations for an operational definition of concussion in sport. ${ }^{4}$ Specific interventions aimed at reducing the number of catastrophic injuries have also been successfully implemented, with the BokSmart programme in South Africa resulting in a $40 \%$ reduction in catastrophic head/neck injuries in junior players. ${ }^{5}$ Programmes based on such specific interventions exist in several nations, which have also disseminated educational resources to all stakeholders in the sport to more widely communicate methods of reducing injury risk. Although these examples of injury reduction strategies should be applauded, Rugby Union has come under increasing pressure regarding the high risk of injury at different levels of the game.

Recently, a group of 70 academics, practitioners and public health professionals proposed that 'harmful contact' (specifically the tackle) should be removed from Rugby Union in schools in the UK. The reasons put forward in support of the proposed action were that the overall risk of injury (particularly severe injury) is unacceptable, that the majority of injuries occur in contact and specifically that the tackle event is the most injurious part of the game. ${ }^{6}$ Such a proposal is not new, but rather the latest iteration of previously raised concerns around the safety of the sport, in academic journals ${ }^{78}$ and in the general media. ${ }^{9}$

A ban on tackling in the sport would, of course, be a significant intervention that would inevitably change the nature of Rugby Union by removing one of its integral parts. This proposal does, however, deserve substantial scrutiny for the possibility that it may be an effective (albeit extreme) means to improve player welfare (a particularly important consideration among children) and also because it focuses discussion on what is currently known and unknown vis-à-vis injury risk in child and adolescent populations in Rugby Union and more generally across different sports. This is crucial because the sport's international governing body 'World Rugby', as well as its member unions, has a legal and moral obligation to take steps to reduce injury risk. ${ }^{6}$

Evaluating a proposal to ban the tackle requires that the evidence that might be offered in support of it be evaluated with stringency. It requires the complete assessment (identification), estimation (understanding of the magnitude and occurrence) and evaluation (determining acceptability) of the risk before decisions can be made about implementing any risk mitigation strategies. ${ }^{10}$

A complete and thorough evaluation of the data is required in order to identify both what is known and what remains unknown so that decisions to reduce risk may be made with the strongest possible evidence base. One of the difficulties faced by governing bodies is determining what constitutes an acceptable level of risk for the sport. In industry, acceptable risks are usually set out in national health and safety legislation; however, no such guidelines exist in the sporting setting. ${ }^{11}$

The purpose of this article is to use the proposal to remove the 'harmful contact' element in Rugby Union to initiate a discussion about both the lack 
of and need for evidence with which to make realistic and effective decisions to reduce injury risk. We first evaluate the current evidence for the injury risk of playing Rugby Union, specifically in the youth population, and then evaluate the assumptions that this research makes. Finally, we aim to identify what is currently not known with the objective of directing future research in such a way that it may answer necessary questions with sound data to direct interventions that will effectively reduce the risk of injury in youth Rugby Union and at other levels of the game.

\section{THE PAUCITY OF YOUTH INJURY DATA}

Foundational to the concept of risk management and injury prevention is that the injury incidence and severity must be documented and described, in order for effective strategies to be developed. The 'sequence of prevention' model as described by van Mechelen et $a l^{12}$ recognises that surveillance in order to inform risk management is the first step towards identifying effective, targeted interventions (which should then be monitored for effectiveness). It is crucial that this step is undertaken, because effective interventions must, by definition, be realistic and obtain the support of the major stakeholders within the specific target population. ${ }^{13}$

With respect to injury surveillance in Rugby Union, particularly among youth players, it must be recognised that neither the incidence nor severity of injury have been thoroughly identified and understood, and thus nor have the specific mechanisms and risk factors for injury. There are a number of generic difficulties that are associated with the implementation of community-based injury surveillance systems in the youth and community population in all sports. First, the availability and resourcing of appropriately qualified medical staff to report injuries accurately is hugely variable and has the potential to lead to inaccurate and inconsistent reporting. This is particularly relevant in schools, many of which lack the resources and dedicated personnel to track injury accurately. The result may be a skewed incidence where the less well-resourced schools are not included in injury surveillance statistics. Whether or not this would result in an overestimate or underestimate of true incidence is uncertain, but warrants consideration when evaluating injury risk in the community game of any sport. Second, calculating exposure accurately in order to determine injury risk is challenging as players often participate in a number of different activities and may only train and play once or twice a week in the sport under research.

As a consequence, the absence of community-based injury surveillance systems and the resultant knowledge gap are not unique to Rugby Union. ${ }^{14}$ However, it should be noted that existing injury surveillance programmes in the professional game $\mathrm{e}^{15-19}$ and more recent emerging surveillance in the community and youth game ${ }^{50-22}$ will enable a more sophisticated and targeted approach to risk reduction than a blanket removal of contact as proposed.

These studies are, however, in their infancy and suffer from a number of methodological challenges that are described subsequently. It is against this backdrop that the proposed strategy to ban tackles must be evaluated.

\section{THE RISK OF INJURY IN CHILDREN AND ADOLESCENTS}

The proposal to remove contact from school Rugby Union cites a high and unacceptable risk of injury as its primary motivation. ${ }^{6}$ However, it is important to note that these two terms are not synonymous. That is, a high risk is not always an unacceptable one per se. ${ }^{11}$ Since the risk of injury in this population is fundamental to the proposed ban, arguments for a high injury incidence in Rugby Union must be considered critically. In this regard, a recent review by Freitag $e a^{23}$ warrants critical evaluation, since it includes the majority of studies that report the risk of injury in youth Rugby Union and Rugby League populations. It identifies the tackle as the most injurious phase of the sport and describes a probability of $28.4 \%$ for a player to be injured in a season (where injury was defined as any physical complaint) and $12.1 \%$ (where injury was defined as a minimum of a 7-day time-loss from match or training participation).

One of the recognised limitations of this review was that the definition of injury varied considerably between the included studies. At one extreme, injuries were defined as any physical symptom reported by participants, regardless of whether medical attention was sought, while at the other end of the spectrum, injuries were defined as those that caused a minimum of 7 days of time-loss from training or match play. This variation alone highlights the difficulties faced by governing bodies in fully understanding and responding to the risk of injury in youth and community populations.

Freitag et $a l^{23}$ reviewed 35 original research studies that explored the risk of injury in youth (under 21) rugby and reported a pooled injury incidence of $26.7 / 1000$ player-hours irrespective of the need for medical attention or time-loss injury. The authors compare this incidence with that reported in the men's professional game (81.0/1000 hours), but this study only included studies that used a time-loss definition of injury. It should be noted that if the definition of injury was brought in line with the time-loss definition ( $>24$ hours absence from match play or training after the day of injury) that has been adopted by the majority of well-established injury surveillance studies in the professional game, ${ }^{24}$ then the reported injury incidence in the youth Rugby playing cohort would be lower. The difference between the incidence reported in the youth and senior professional cohorts would therefore be larger. ${ }^{24}$

Indeed, the authors also calculated the pooled incidence for the eight studies that used a 7-day time-loss injury definition and, as expected, the incidence of injury decreased substantially to $10.3 / 1000$ hours. ${ }^{23}$ The reliability and accuracy of reporting less severe injuries ${ }^{25}$ has been questioned where medical resources and a controlled environment are both commonplace. On the other hand, reporting all injuries may prevent the underreporting of injuries. ${ }^{26}$ The criteria used to register injury data should therefore be selected with the specific study population and environment in mind, ${ }^{27}$ and it is arguable that the 7-day time-loss definition is the most accurate and reliable in this setting. The importance of the magnitude of these calculated incidences will become apparent later in this review.

Perhaps what is more concerning, however, is the interpretation of the pooled incidence data reported by Freitag et al. ${ }^{23}$ The pooled data approach presents a mean incidence across the full range of ages from 6 to 21, despite the obvious and recognised importance of separating injury risk into age groups. This is because injury risk in Rugby Union has already been shown to be highly influenced by age, ${ }^{28}$ and mean data can often mask significant individual differences (a similar observation has been made previously when considering position as a risk factor for injury in the adult game ${ }^{29}$ ). It should be noted that the association between age and injury is not unique to Rugby Union. In a recent meta-analysis of youth injuries in soccer, it was concluded that the risk of injury appeared to increase with age. ${ }^{30}$

The study by Haseler $e t$ al, while acknowledged as having a small sample size with only 39 injuries over the observation 
period, found that injury incidence (using a time-loss definition) increased with age, identifying that those players aged 9-11 presented with a mean injury incidence of $6.0 / 1000$ hours, while players aged 17 years had an incidence of $49.3 / 1000$ hours. It is likely that this risk increases even further in the Under-20 age group, where World Rugby's surveillance studies find the injury incidence ranging between 55.0-64.0/1000 hours at the annual Under-20 Rugby World Cups. ${ }^{31}$ Indeed, the studies in the sample of 35 used by Freitag et $a l^{23}$ to calculate pooled incidence also confirm this progressive increase of injury risk with age. For instance, Durie and Munroe find an increase in incidence from 20/1000 hours in U13 players to 65.8/1000 hours in first XV rugby players, while Lee (1996) found that injury incidence increased progressively from the age of 11 years (15.3 injuries per 1000 player seasons) to the age of 19 years (230.8 injuries per 1000 injuries per 1000 player seasons).

The implication of this progressive increase with age is that grouping players aged 9-12 with those aged 18-20 for analysis reveals nothing on which an informed decision can be made about how to mitigate against risk at any specific age. Instead, it offers a distortion of the 'true' risk of injury and is unsuitable for use to argue policy change and injury prevention strategies. Such a distortion becomes apparent when the substance of the proposed tackle ban is evaluated. Freitag $e t a l^{23}$ conclude in their review that $28.4 \%$ of Rugby Union players will be injured in a season (this figure was $12.1 \%$ when using the 7 -day timeloss injury definition), but the cohort they use to derive these numbers is inappropriate, especially when one considers that the reported rate of injury occurrence per player varies enormously from one injury every 50 matches $^{32}$ to one injury every 168 matches $^{28}$ in the U13 age group. In the U18 age group, the reported values in the same studies range between one injury every four matches ${ }^{32}$ to one injury every 35 matches. ${ }^{28}$ Such large differences are, unsurprisingly, in part the result of differences in the injury definition, as described.

Since the research and data presented in this meta-analysis are fundamental to a proposed ban on tackles in school rugby, it seems necessary to ask the question whether the risk has been overstated as a result of the creation of 'pooled risk', which then invites 'pooled interventions' that are most likely to not be 'fit for purpose'. There can be no doubt that policymakers would view a proposal differently when injury risk is $11.9 / 1000$ hours (1 injury per player expected every 168 matches) in the U13 age group (28) using a >24-hour time-loss definition to 216.0/ 1000 hours (1 injury per player every 4 matches) in the U 18 age group ${ }^{33}$ using a physical complaint definition of injury.

\section{THE RISK OF YOUTH RUGBY COMPARED TO OTHER SPORTS}

Another material consideration to this debate is to understand how the risk of injury in youth Rugby Union compares to the risk of injury in other sports, and in other activities. The aforementioned studies on Rugby Union find an injury incidence of between 3.7 and 109 injuries/1000 hours in children younger than 15 years of age, ${ }^{23} 28$ an extraordinarily large range that highlights the influence of the definition of injury and specific context on injury risk. Spinks and $\mathrm{McClure}^{34}$ provide evidence for the risk of injury in youths (16 and under) from a range of other sports, including soccer, baseball, basketball, ice hockey and American football. Notwithstanding the complexity and aforementioned challenges of direct comparisons when the definition of injury ranges from more inclusive definitions such as medical attention to a more exclusive definition such as time-loss of greater than a week, it is concluded that no sport stands out as being more injurious than others.

Similarly, in a small cohort of Rugby Union, Rugby League and Netball youths (6-15 years) in New Zealand, the reported injury incidences were $15.5,13.0$ and 24.5 injuries/1000 hours, respectively. ${ }^{35}$ Interestingly, a greater proportion of injuries observed in netball caused the injured player to miss at least 1 week of play than was the case for Rugby Union, where 96\% of injuries were classified as 'minor', and the injured player was able to play within 1 week. ${ }^{35}$

The difficulty in comparing the incidence and severity of injury across sports highlights some substantial challenges to our current understanding of injury epidemiology in youth sport. The definition of injury has varied with significant implications for calculated incidence; also, the ability to document exposure time and accurately diagnose injuries creates a complexity that simple and direct comparisons cannot overcome. However, the available evidence, when considering these challenges, suggests that the risk of injury in Rugby Union is not disproportionately high in children and that around 15 years of age appears to be when the incidence of injury in contact and collision sports increases in comparison to non-contact sports.

In summary, the central point is that the risk of participation in Rugby Union, while warranting focus and continued efforts for primary injury prevention, does not stand out beyond that of other popular sports. This is not necessarily offered as a counter to a proposal to ban either Rugby Union or the tackle per se, because all sports must act in any way possible to reduce any unnecessary risk for its participants. However, it does provide perspective when responding to such proposals and the isolated presentation of data supporting those proposals.

\section{REDUCING RISK IN RUGBY UNION: UNKNOWN VARIABLES AND POTENTIAL INTERVENTIONS}

We have previously mentioned the enormous challenge in trying to accurately document injury incidence across different sports at the community level to enable comparisons to be made, as well as to allow within-sport longitudinal analysis that might guide the evaluation of interventions.

In addition, a recent letter published in the British Medical Journal has outlined the efforts of conducting injury surveillance studies in the community game in England ${ }^{36}$ and separately ${ }^{37}$ highlighted the ongoing injury surveillance and injury intervention strategies that are currently being undertaken in schoolboy Rugby Union. Injury prevention programmes such as BokSmart in South Africa ${ }^{5}$ and the RugbySmart programme in New Zealand offer intervention strategies that have been shown to reduce serious injury incidence. In agreement with Trewartha and Stokes, ${ }^{36}$ we would contend that while emerging and limited, Rugby Union's community injury surveillance systems and proactive approach to reducing the risk of injury in the amateur game are in fact ahead of the majority of other sports.

Currently, the impact that removing the tackle at an early age may have on injury risk later in the participation cycle is unknown. Indeed, the reality is that at some age, tackling will be part of Rugby Union, and it is true that this aspect of the sport is most injurious, accounting for between 50\% and 70\% of injuries in all forms of the game. ${ }^{15} 3839$ It has also been documented that poor or inappropriate tackle technique is more likely to be observed in tackles leading to head injuries ${ }^{40}$ and all contact injuries $^{41}$ in high-level Under-18 players. Furthermore, McIntosh $e^{2} a^{42}$ found that younger (Under-15) players more often used a passive shoulder tackle, whereas older players used 
an active shoulder tackle more frequently. The younger players were significantly less likely to be injured during the tackle, a finding supporting the general trend described previously regarding the association between age and injury risk. ${ }^{23} 28$

Collectively, these findings have some important implications. First, they suggest that poor tackle technique plays a critical role in injury. Second, the type of tackle used can contribute to significantly reducing the risk of injury in the tackle, though this may have implications for the performance outcomes in the tackle. We interpret this to hypothesise that the proper teaching of good technique, as well as management and guidance of which type of tackle young players are taught and expected to use, can have material effects on injury risk during Rugby Union participation.

To the best of our knowledge, there have not been any prospective studies that have looked at the influence of technical interventions and coaching delivery on the risk of injury in Rugby Union. Therefore, the utility of this intervention in this setting remains unexplored and warrants further consideration. Similarly, the specific types of tackles that are relatively safer or more injurious have only been described in relatively basic terms ${ }^{38} 4243$ in the adult game, and the relative dearth of controlled studies in this area emphasises the fundamental need for ecologically valid research on which real-world decisions can be made.

The danger then, of removing the tackle from compulsory rugby in schools as has been proposed, is that it would deny the need and opportunity to many young players to begin learning a skill set which evidence suggests is both effective (for performance) and protective later in their rugby playing careers. Since the tackle is an inevitable and important part of the sport at some stage, the effect of a tackle ban may be to dramatically reduce risk in that cohort where it is applied, but to create similar increases in older cohorts who are later exposed to full contact rugby.

The introduction of tackling later in life may be a matter of particular concern because the moment when tackling becomes legal would coincide with the age range where previous studies have found the greatest incidence of injury, presumably because of the increased speed, size and physicality of the game at that age. Indeed, physical stature and level of competition were risk factors for injury in a recent schoolboy surveillance study. ${ }^{20} \mathrm{~A}$ similar argument was made in the recent position statement from the American Academy of Pediatricians who did not support the banning of the tackle in youth American Football. ${ }^{44}$

One example comes from ice-hockey, where it has been shown that injury incidence is threefold higher in youth icehockey leagues that allow body-checking than in those that do not. ${ }^{45}$ However, when body-checking was introduced at the age of 13 , those players who had experience with body-checking had a $33 \%$ reduction in severe injury risk compared to those who did not. ${ }^{46}$ Whether a delay in technical training may increase later injury risk in rugby remains unknown. However, this warrants further investigation before the tackle is banned without any data to support or refute the potential of negative effects arising later in the participation cycle.

Furthermore, a mix or hybrid of types of rugby with different tackle conditions based on age should be considered to manage and reduce exposure to potentially injurious situations without removing them altogether. This may result in a reduction of the risk without fundamentally changing the nature of the sport, or potentially creating an increase in risk at a later age. One way in which this could be achieved would be for the Governing Body to consider targeted law changes at various ages that govern the legality of certain tackle types and heights and even limiting the amount of contact in training, although this would be nearly impossible to govern on a nationwide and worldwide scale.
Conversely, evidence may suggest that a minimum threshold for the amount of contact training undertaken is required if reducing contact practice increases the risk of injury in matches. These interventions can only be carried out, however, if the implications of these changes are fully understood. This requires that the tackle and the associated risk of injury in specific levels of competition and ages should be understood in far greater detail than is currently the case.

Another consideration, given the large differences in biological development and maturation between children of similar ages $^{47}$ and the early indication that physical stature is a risk factor for injury in schoolboy Rugby Union, ${ }^{20}$ might be to consider alternative approaches to the banding of children into teams that may be pursued as a strategy. One approach might be to adopt the so-called 'bio-banding' method, where children are grouped together by physical maturity rather than chronological age to minimise mismatches. Investigations into the potential utility in soccer are in their infancy, ${ }^{48}$ but from an injury risk perspective, given the contact nature of Rugby Union, this approach warrants investigation in this setting, even though it has previously been explored by individual nations.

This approach in itself poses some unique challenges, principally because psychological development does not necessarily occur at the same rate as biological change. ${ }^{49}$ This is important because sports participation, particularly in children, has a significant social component that may be compromised by this method. ${ }^{50}$ However, a compromise using a hybrid approach, where children switch between playing in a weight and biobanded teams, as well as teams selected on the basis of ability (the status quo), may be possible. This would expose young players to a range of different team situations and environments, which may even include different rules related to the tackle, which may reduce injury risk and optimise player development, skill acquisition and welfare.

\section{RECOMMENDED RESEARCH ACTIONS FOR RUGBY UNION IN THE YOUTH GAME}

One of the positive outcomes of this debate is that it has highlighted a number of areas of future research particularly applicable to community and youth participation.

- First, longitudinal injury surveillance in youth populations is crucial in order to be able to understand the magnitude of the injury problem and to direct future risk mitigation strategies. In order to overcome the complexities and challenges faced by international and national governing bodies in this area (medical resource, player contact time and accurate measurement of exposure), it is likely that the utility of capturing this information via different technologies (such as app or cloud based) should be explored in order to increase the feasibility of nationwide injury surveillance data collection.

- Given the large definitional and reporting variation observed in studies that have focused primarily on the epidemiology of injury in community and youth populations, and the consequential difficulties in comparing reported findings, there appears to be a need to achieve greater consensus on the reporting of injury data, including the definition in amateur levels of the game.

- In a similar fashion to the professional game, available evidence from the community and youth setting identifies the tackle as the most injurious game event. In order to fully understand the risk factors for injury associated with the tackle, a video analysis study should be undertaken in these populations to inform injury prevention strategies. The difficulty of obtaining good quality video footage in these populations is acknowledged. 
- Directed by research findings on tackles and mechanisms of injury, the effects of specific and targeted coaching of tackle technique should be investigated.

- The impact that bio-banding may have on the risk of injury in this setting should be explored by the international governing body and its member unions as a potential way to mitigate against injury risk in younger players.

\section{CONCLUSION}

In conclusion, the proposal to remove all contact from youth rugby should not be supported by Rugby Union governing bodies. When the available evidence is taken collectively, it is clear that there remain a host of unanswered questions, gaps in the current knowledge and scenarios specific to the youth setting that cannot be fully understood at this time. As a consequence, an intervention such as has been proposed may be unnecessary and may also lead to unintended consequences such as an increase in the risk of injury later in participation.

It seems clear that up to the period of adolescence (age 15 years), the risk of injury in Rugby Union is low and comparable to other major sports. There is little evidence to suggest that Rugby Union exposes youths to risks that are any greater than those involved in a range of team sports. The available evidence suggests that physical development and the nature of the sport, including tackle type change after adolescence, may augment the risk of injury. This risk is strongly linked to poor technique, and it may be disingenuous to deny young rugby players the opportunity to be exposed to good teaching of proper technique during formative years, given that it is inevitable that they will be required to tackle if they persist with the sport to a certain age.

\section{What are the findings?}

- Recent bans to ban the tackle from schools rugby invite debate over the safety of the sport of Rugby Union.

- Rugby injury incidences have been documented, but with significant methodological differences, including injury definition. This affects the generalisability of findings and the conclusions drawn from such research, including the proposal to ban tackling.

- That evidence which does exists suggests that age is a significant influencer of injury risk, with Rugby Union having a similar risk to other common sports until adolescence.

- A complete ban on tackles is unnecessary and may be detrimental.

- A number of research question require investigation in order to identify effective, targeted strategies to reduce injury risk.

\section{How might it impact on clinical practice in the future?}

- The review focuses primarily on the paucity of research data with which to guide clinical practice.

- Clinical practitioners, including those involved in the sport of Rugby Union, must address the need for well-controlled injury surveillance data.

- Standard definitions for injury exist, but varying contexts have made the use of a single definition difficult. Clinical practice must address this.
Correction notice This paper has been amended since it was published Online First. The following wording has been added to the end of the paper's title: 'A critical review'.

Acknowledgements The authors would like to thank Dr Matthew Cross for his valuable input on the manuscript.

Contributors RT conceived and wrote the manuscript. MR and EV edited the manuscript.

Competing interests Two authors (RT and MR) are salaried employees at World Rugby (Pty) Ltd, the governing body for the sport of Rugby Union globally.

Provenance and peer review Not commissioned; externally peer reviewed.

\section{REFERENCES}

1 Taylor AE, Kemp S, Trewartha G, et al. Scrum injury risk in English professional Rugby Union. Br J Sports Med 2014;48:1066-8.

2 Cazzola D, Preatoni E, Stokes KA, et al. A modified prebind engagement process reduces biomechanical loading on front row players during scrummaging: a cross-sectional study of 11 elite teams. Br J Sports Med 2015;49:541-6.

3 Fuller GW, Kemp SP, Decq P. The International Rugby Board (IRB) pitch side concussion assessment trial: a pilot test accuracy study. $\mathrm{Br} J$ Sports Med 2015;49:529-35.

4 Raftery M, Kemp S, Patricios J, et al. It is time to give concussion an operational definition: a 3-step process to diagnose (or rule out) concussion within $48 \mathrm{~h}$ of injury: World Rugby guideline. Br J Sports Med 2016;50:642-3.

5 Brown JC, Verhagen $E$, Knol D, et al. The effectiveness of the nationwide BokSmart rugby injury prevention program on catastrophic injury rates. Scand J Med Sci Sports 2015;26:221-5.

6 SportCIC. Open Letter: preventing injuries in children playing school rugby 2016 (cited 11 March 2016). http://www.sportcic.com/resources/Open\%20Letter\% 20SportCIC\%20March1st\%202016.pdf

7 Carter M. The unknown risks of youth rugby. BMJ 2015;350:h26.

8 Freitag A, Kirkwood G, Pollock AM. Rugby injury surveillance and prevention programmes: are they effective? BMJ 2015;350:h1587.

9 Pollock AM. World Rugby isn't doing enough to protect young players from head injuries. The Guardian 2015.

10 Fuller C, Drawer S. The application of risk management in sport. Sports Med 2004:34:349-56.

11 Fuller CW. Managing the risk of injury in sport. Clin J Sports Med 2007;17:182-7.

12 van Mechelen W, Hlobil H, Kemper HC. Incidence, severity, aetiology and prevention of sports injuries. Sports Med 1992;14:82-99.

13 Finch C. A new framework for research leading to sports injury prevention. I SCi Med Sport 2006;9:3-9.

14 Ekegren CL, Gabbe BJ, Finch CF. Sports injury surveillance systems: a review of methods and data quality. Sports Med 2016;46:49-65.

15 Brooks JH, Fuller CW, Kemp SP, et al. Epidemiology of injuries in English professional Rugby Union: part 1 match injuries. Br J Sports Med 2005;39:757-66.

16 Brooks JH, Fuller CW, Kemp SP, et al. Epidemiology of injuries in English professional Rugby Union: part 2 training Injuries. Br J Sports Med 2005;39:767-75.

17 Fuller CW, Laborde F, Leather RJ, et al. International rugby board Rugby World Cup 2007 injury surveillance study. Br J Sports Med 2008:42:452-9.

18 Quarrie K, Alsop J, Waller AE, et al. The New Zealand rugby injury and performance project. VI. A prospective cohort study of risk factors for injury in Rugby Union football. Br J Sports Med 2001;35:157-66.

19 Rugby Football Union. The Professional Rugby Injury Surveillance Project: The 2014-15 Annual Report 2016.

20 Archbold HA, Rankin AT, Webb M, et al. RISUS study: Rugby Injury Surveillance in Ulster Schools. Br J Sports Med Published Online First: 23 Dec 2015. doi:10.1136/ bjsports-2015-095491

21 Gianotti SM, Quarrie KL, Hume PA. Evaluation of RugbySmart: a rugby union community injury prevention programme. J Sci Med Sport 2009;12:371-5.

22 Roberts SP, Trewartha G, England M, et al. Epidemiology of time-loss injuries in English community-level Rugby Union. BMJ Open 2013;3:e003998.

23 Freitag A, Kirkwood G, Scharer $S$, et al. Systematic review of rugby injuries in children and adolescents under 21 years. Br J Sports Med 2015;49:511-19.

24 Williams S, Trewartha G, Kemp S, et al. A meta-analysis of injuries in senior men's professional Rugby Union. Sports Med 2013;43:1043-55.

25 Orchard J, Hoskins W. For debate: consensus injury definitions in team sports should focus on missed playing time. Clin J Sports Med 2007;17:192-6.

26 Hodgson L, Gissane C, Gabbett TJ, et al. For debate: consensus injury definitions in team sports should focus on encompassing all injuries. Clin J Sports Med 2007;17:188-91.

27 Clarsen B, Bahr R. Matching the choice of injury/illness definition to study setting, purpose and design: one size does not fit all! Br J Sports Med 2014;48:510-12. 
28 Haseler CM, Carmont MR, England M. The epidemiology of injuries in English youth community rugby union. Br J Sports Med 2010;44:1093-9.

29 Cahill N, Lamb K, Worsfold P, et al. The movement characteristics of English premiership rugby union players. J Sports Sci 2013;31:229-37.

30 Faude 0 , Rößler $R$, Junge $A$. Football injuries in children and adolescent players: are there clues for prevention? Sports Med 2013;43:819-37.

31 Fuller CT, Taylor A. World Rugby Surveillance: U20 Championship-Injury Surveillance Summary of Results: 2008 to 2015. 2015. http://playerwelfare.worldrugby.org/?

32 Durie R, Munroe A. A prospective survey of injuries in a New Zealand schoolboy rugby population. NZ I Sports Med 2000;28:84-91.

33 King D. Incidence of injuries in the 2006 New Zealand national junior rugby league competition. NZ J Sports Med 2006;34:21.

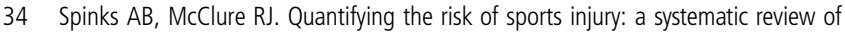
activity specific rates for children under 16 years of age. $\mathrm{Br} /$ Sports $\mathrm{Med}$ 2007;41:548-57; discussion 557

35 Pringle RG, McNair P, Stanley S. Incidence of sporting injury in New Zealand youths aged 6-15 years. Br J Sports Med 1998;32:49-52.

36 Trewartha G, Stokes K. Available evidence on risk of injury in youth rugby. BMJ 2015:350:h434.

37 Hislop M, Stokes K, Williams S, et al. The efficacy of a movement control exercise programme to reduce injuries in youth rugby: a cluster randomised controlled trial. BMJ 2016;2:e000043

38 Fuller CW, Brooks JH, Cancea RJ, et al. Contact events in Rugby Union and their propensity to cause injury. Br J Sports Med 2007;41:862-7.

39 Palmer-Green DS, Stokes KA, Fuller CW, et al. Match injuries in English youth academy and schools Rugby Union: an epidemiological study. Am I Sports Med 2013;41:749-55.
40 Hendricks $S, O^{\prime}$ connor $S$, Lambert $M$, et al. Contact technique and concussions in the South African under-18 Coca-Cola Craven week Rugby tournament. Eur I Sports Sci 2015; 15:557-64.

41 Burger N, Lambert MI, Viljoen W, et al. Tackle technique and tackle-related injuries in high-level South African Rugby Union under-18 players: real-match video analysis. Br J Sports Med 2016;50:933-9.

42 McIntosh AS, Savage TN, McCrory P, et al. Tackle characteristics and injury in a cross section of rugby union football. Med Sci Sports Exerc 2010;42:977-84.

43 Quarrie KL, Hopkins WG. Tackle injuries in professional rugby union. Am I Sports Med 2008;36:1705-16.

44 Brenner JS, LaBella CR, Brooks MA, et al. Tackling in youth football. Pediatrics 2015;136:e1419-e30.

45 Emery CA, Kang J, Shrier I, et al. Risk of injury associated with body checking among youth ice hockey players. JAMA 2010;303:2265-72.

46 Emery C, Kang J, Shrier I, et al. Risk of injury associated with bodychecking experience among youth hockey players. Can Med Assoc J 2011;183: $1249-56$.

47 Until K, Cobley S, O'Hara J, et al. Considering maturation status and relative age in the longitudinal evaluation of junior rugby league players. Scan J Med Sci Sports 2014;24:569-76

48 Doward J. Bio-banding: how scientists can help late developers become sporting superstars. The Guardian 2015.

49 Vaeyens $\mathrm{R}$, Lenoir $\mathrm{M}$, Williams AM, et al. Talent identification and development programmes in sport. Sports Med 2008;38:703-14.

50 Allender S, Cowburn G, Foster C. Understanding participation in sport and physical activity among children and adults: a review of qualitative studies. Health $E d$ Res 2006;21:826-35. 